\title{
Tailored Degree of Functionalization and Length Preservation of Multiwalled Carbon Nanotubes by an Optimized Acid Treatment Process
}

\author{
Vinícius G. Castro, ${ }^{a, b}$ Ingrid B. Costa, ${ }^{a}$ Magnovaldo C. Lopes, ${ }^{a}$ Rodrigo L. Lavall, ${ }^{a}$ \\ Kátia C. S. Figueiredo ${ }^{b}$ and Glaura G. Silva ${ }^{*, a}$
}

${ }^{a}$ Departamento de Química, Instituto de Ciências Exatas and

${ }^{b}$ Departamento de Engenharia Química, Escola de Engenharia, Universidade Federal de Minas Gerais, 31270-901 Belo Horizonte-MG, Brazil

\begin{abstract}
The introduction of oxygen groups in carbon nanotubes is considered crucial for many applications. However, there is a lack of controlled functionalization methods which ensure nanotubes with specific property values according to each interest. In this work, acid treatments of multiwalled carbon nanotubes (MWCNTs) employing an optimized ultrasound process with moderate heating and stirring were studied by means of a factorial design. The functionalized nanotubes were characterized by thermogravimetry, elemental analysis, Raman spectroscopy, electron microscopy and water stability tests. Statistic models were fitted for the degree of functionalization and length reduction of MWCNTs. Temperature was identified as a key parameter to produce more functionalized MWCNTs with less structural damage. The properties of the functionalized MWCNTs can be tailored by the choice of parameters exploited in the statistical models developed to enable different end-use requests, such as for polymeric composites or biorelated applications, which is the original contribution of this work.
\end{abstract}

Keywords: carbon nanotubes, functionalization, length distribution, factorial design, statistical modeling

\section{Introduction}

The potential applications of carbon nanotubes (CNTs) are widely recognized, including areas such as sensing, ${ }^{1}$ biomedicine, ${ }^{2}$ energy storage ${ }^{3,4}$ and polymeric composites. ${ }^{3-5}$ Many products using CNTs are already on the market and the price reduction of CNTs in recent years, especially for multiwalled carbon nanotubes (MWCNTs), is contributing for their use in large-scale. ${ }^{3,4}$ However, the poor dispersion and weak interfacial interactions of CNTs with other materials are the major limitations to its dispersion and fabrication of composites with enhanced properties.,

There are several studies of surface modifications of CNTs to improve its dispersion and chemical compatibility. ${ }^{6,7}$ The different methodologies involve covalent modifications and non-covalent approaches. Noncovalent modifications present the advantage of altering in a lower degree the structure of the CNTs, but the interaction between the CNTs and the modifier molecules are based on weak forces such as van der Waals and $\pi$ - $\pi$ bonds. ${ }^{7,8}$

*e-mail: glaura.goulart@gmail.com, glaura@qui.ufmg.br
Among the different approaches for covalent modification, acid treatments are the most reported in literature, generally using nitric acid $\left(\mathrm{HNO}_{3}\right)$ or a mixture of $\mathrm{HNO}_{3}$ and sulfuric acid $\left(\mathrm{H}_{2} \mathrm{SO}_{4}\right){ }^{9-12}$ The acid treatments introduce oxygen functional groups on the surface of the CNTs, especially carboxyls, phenolic hydroxyls and lactones/lactols.,10,13,14 The inserted functional groups, particularly carboxyls, are also basis for subsequent functionalization, such as amidation, alkylation, esterification and thiolation. , $^{6,15,16}$

Table 1 presents the main techniques reported in the literature for reacting CNTs with $\mathrm{HNO}_{3}$ or $\mathrm{HNO}_{3} / \mathrm{H}_{2} \mathrm{SO}_{4}$, which are based on a single step treatment or a two-step sequence. The most common processes use ultrasonic bath, ${ }^{17-20}$ reflux at high temperatures ${ }^{9,12,13,20-26}$ (occasionally under magnetic stirring $)^{10,27,28}$ or ultrasonic bath followed by reflux. ${ }^{14,23,29-31}$ Most documents that describe the use of ultrasonic bath does not cite any heating or occasionally mention the temperature of $40{ }^{\circ} \mathrm{C},{ }^{17}$ which can be naturally achieved due to the ultrasonic power delivered from some equipment. There are few references that describe the use of ultrasound with moderate heating. ${ }^{32,33}$ Some researches also reported the use of microwave..$^{23,34-36}$ 
Table 1. Main techniques used for acid treatment of CNTs

\begin{tabular}{lccccccccc}
\hline \multirow{2}{*}{ References } & \multicolumn{3}{c}{ Step 1 } & \multicolumn{1}{c}{ Step 2 } \\
\cline { 2 - 9 } & U & MH & R & S & M & U & MH & R & S \\
\hline $17-20$ & $\times$ & & & & & & & & \\
$9,12,13,20-26$ & & & $\times$ & & & & & & \\
$10,27,28$ & & & $\times$ & $\times$ & & & & & \\
$14,23,29-31$ & $\times$ & & & & & & & & \\
11 & & $\times$ & & $\times$ & & $\times$ & & & \\
32 & $\times$ & $\times$ & & & & & & & \\
33 & $\times$ & $\times$ & & $\times$ & & & & & \\
$23,34-36$ & & & & & $\times$ & & & & \\
\hline
\end{tabular}

U: ultrasound; MH: moderate heating; R: reflux; S: stirring; M: microwave.

Besides the functionalization of CNTs, acid treatments also result in damages to its structure with introduction of defects, reduction of length ${ }^{7,19}$ and formation of oxygenated carbonaceous fragments. ${ }^{13,34}$ Thus, the development of methodologies that combine a high degree of functionalization with proper preservation of CNTs is of great importance. ${ }^{10,11}$ Despite the length being one of the main parameters to define the applications of CNTs, the statistical evaluation of its distribution after functionalization is addressed by few studies in the literature. ${ }^{19,26}$ Furthermore, the most appropriate set of length and degree of functionalization varies with each application of MWCNTs. For instance, highly functionalized and short MWCNTs with narrow length distribution are preferable for bio-related applications. ${ }^{19,37}$ MWCNTs with a substantial functionalization and a higher preservation of its aspect ratio are desirable for polymeric composites. ${ }^{5,38}$

In the present work, we statistically evaluated the advantages of an acid treatment process of MWCNTs with integration of ultrasound, moderate heating and mechanical stirring. The correlation between degree of functionalization and length reduction was analyzed, as well as the applicability of the method to larger scales. Some representative MWCNTs samples, by considering the statistical analysis results, were characterized by Raman spectroscopy, transmission electron microscopy (TEM) images and by dispersion stability in water for 30 days. Thermogravimetric analysis (TGA) and elemental analysis were used as basic methods to determine degree of functionalization. Scanning electron microscopy (SEM) images were analyzed with ImageJ to access length distribution. The quantitative analysis of these variables intends to provide a valuable contribution to researchers and developers looking to apply MWCNTs with the potential to tailor the MWCNTs characteristics based on the modeling of a wide range of experimental parameters.

\section{Experimental}

\section{Materials}

The MWCNTs used in this study were provided by the Nanomaterials Laboratory from the Physics Department of Federal University of Minas Gerais (UFMG), Brazil, with purity higher than $95 \%$, average diameter of $17 \mathrm{~nm}$, length distribution from few micrometers until $30 \mu \mathrm{m}$, average length of $5 \mu \mathrm{m}$ by arithmetic mean and $10 \mu \mathrm{m}$ by weighted mean. Nitric and sulfuric p.a. acids were supplied by Synth.

\section{Acid treatments of MWCNTs}

Acid treatments were initially conducted in ultrasonic bath (sonication power of $220 \mathrm{~W}$, frequency of $37 \mathrm{kHz}$ ) at $50{ }^{\circ} \mathrm{C}$ for $3 \mathrm{~h}$ to analyze the scalability of the process and the necessity of stirring. The process was evaluated for $0.8 \mathrm{~g}$ of MWCNTs with $48 \mathrm{~mL}$ of concentrated $\mathrm{H}_{2} \mathrm{SO}_{4} / \mathrm{HNO}_{3}$ (3:1 by volume) and for a proportional scale-up to $3.0 \mathrm{~g}$ and $176 \mathrm{~mL}$ of the same materials. It was analyzed the necessity of including mechanical stirring at $430 \mathrm{rpm}$ for the treatment of $3.0 \mathrm{~g}$.

To evaluate the statistical influence of the main variables involved (time, temperature and stirring) in the ultrasonic assisted acid treatments, it was performed a full $2^{3}$ factorial design ( 3 factors in 2 levels) with addition of center point in triplicate. The factors and levels are described in Table 2. The two levels are represented as -1 and +1 and the center point is represented as 0 . There were a total of 11 experiments run in random order, 8 associated with all combinations of levels -1 and +1 plus the triplicate at the center point $(0)$. For all treatments $3 \mathrm{~g}$ of MWCNTs and $176 \mathrm{~mL}$ of concentrated $\mathrm{H}_{2} \mathrm{SO}_{4} / \mathrm{HNO}_{3}$ (3:1 by volume) were used.

Table 2. Factors and levels of the factorial design

\begin{tabular}{lccc}
\hline Factor & \multicolumn{3}{c}{ Level } \\
\cline { 2 - 4 } & -1 & 0 & +1 \\
\hline $\mathrm{T} /{ }^{\circ} \mathrm{C}$ & 45 & 50 & 55 \\
$\mathrm{t} / \mathrm{h}$ & 2 & 3 & 4 \\
$\mathrm{~S} / \mathrm{rpm}$ & 290 & 430 & 570 \\
\hline
\end{tabular}

T: temperature; t: time; $S$ : stirring.

The washing and separation of the functionalized MWCNTs suspensions were conducted by its dilution in deionized water, filtration on sintered glass with pore diameter of 10-16 $\mu \mathrm{m}$ and continuous washing with deionized water until reaching $\mathrm{pH}$ 7. The material in the filtration system was constantly stirred to increase the flow rate. Although the literature usually reports the 
use of polymeric membranes with pore diameter lower than $1 \mu \mathrm{m}$, which represent higher costs, sintered glass is generally efficient for the filtration of MWCNTs due to its aggregation during filtration. The retained MWCNTs were dried at $100{ }^{\circ} \mathrm{C}$ for $8 \mathrm{~h}$.

\section{Characterization}

TGA was performed on a Q5000 apparatus (TA instruments) under synthetic air atmosphere with a heating rate of $5{ }^{\circ} \mathrm{C} \mathrm{min}^{-1}$ from 20 to $900{ }^{\circ} \mathrm{C}$. Elemental analysis was conducted on a Thermo Flash 2000 Analyser and the average of three measurements for each sample was determined. SEM was carried out on a cannon emission field effect Quanta 200 - FEG/FEI, with samples prepared by ultrasonicating the MWCNTs in isopropyl alcohol and dripping them onto a 200 mesh Holey Carbon copper grid. The length distribution of MWCNTs was determined by the software ImageJ based on SEM images. The statistical analyses were conducted through data processing on Minitab software (Minitab Inc.), considering the degree of functionalization (obtained from TGA) and length reduction (obtained from SEM images) as the response variables.

Raman spectroscopy was carried out on a Micro-Raman Senterra Bruker equipped with a liquid nitrogen-cooled $\mathrm{CCD}$ detector, Ar-Kr laser at excitation in $514.5 \mathrm{~nm}$ and acquisition of scan with duration of $60 \mathrm{~s}$. TEM was conducted on a FEI TECNAI G2 microscope with a tungsten filament electron gun of $200 \mathrm{kV}$ and the same sample preparation used for SEM. The dispersion stability of the nanotubes was investigated by ultrasonicating $5 \mathrm{mg}$ of MWCNTs in $15 \mathrm{~mL}$ of deionized water for $15 \mathrm{~min}$ and taking photographs of the state of dispersion after 30 days by a digital camera to ensure a long-term evaluation. The yield of the treatments was assessed by weighing the dry MWCNTs before and after each treatment.

\section{Results and Discussion}

\section{Thermogravimetric analysis}

TGA provides useful information about functionalized CNTs and is usually performed in air ${ }^{11,12,15,18,32}$ or nitrogen. ${ }^{11,17,19,32}$ The analyses in both atmospheres are relevant, but the evaluation in air has the advantage of also exhibit the decomposition of CNTs. The TGA results obtained in air generally present decomposition in three stages. The first stage is related with the presence of adsorbed water/gases. The second one is attributed to the decomposition of functional groups generated in the acid treatments, which we assume as the degree of functionalization of the modified nanotubes. The final stage, at higher temperatures, corresponds to the thermoxidation of CNTs. The temperature defined for the end of water removal and the initial decomposition of functional groups (especially carboxyl groups) is generally in the range between 100 and $150{ }^{\circ} \mathrm{C} \cdot{ }^{15,21,26} \mathrm{An}$ usual range to analyze the degree of functionalization is from 120 to $400{ }^{\circ} \mathrm{C},,^{15}$ which was used in this work once no weight loss was observed in this temperature range for the pristine MWCNTs.

The degree of functionalization was reduced from 7.7 to 5.1 mass \% with the scaling of 0.8 to $3.0 \mathrm{~g}$ of MWCNTs without presence of stirring, which represents a decrease of $34 \%$ in the functionalization. Nevertheless, when mechanical stirring was introduced in the treatment with $3 \mathrm{~g}$, a similar degree of functionalization (7.8 mass $\%$ ) was obtained. Therefore, the ultrasonic process with moderate heating is sufficient to promote substantial functionalization for small masses of MWCNTs, but the presence of stirring is necessary to maintain the results in larger scales.

Figure 1 shows the TGA curves for specific treatments of the factorial design and Table 3 lists the degree of functionalization for all oxidized MWCNTs involved in this design.

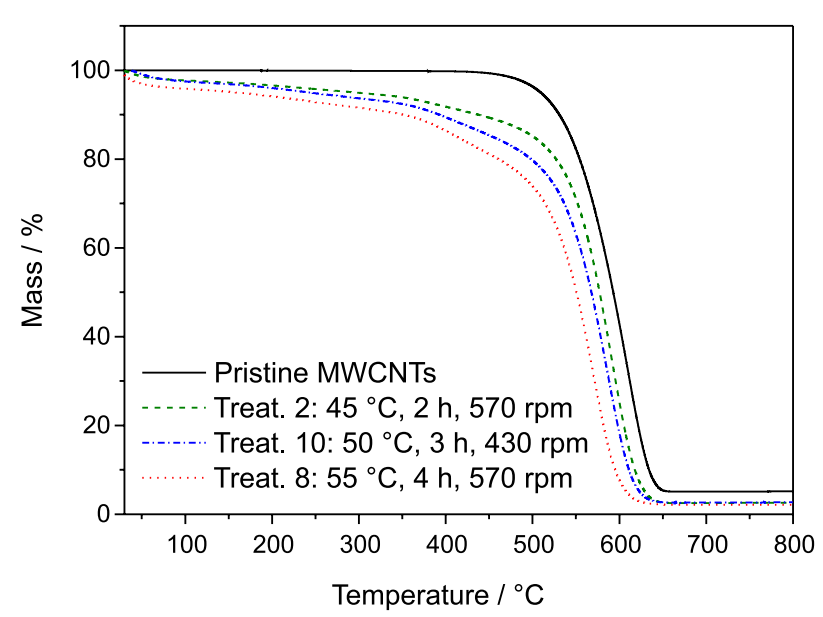

Figure 1. TGA analysis of the oxidized MWCNTs produced by the factorial design.

The degree of functionalization varied from 5.7 to 9.2 mass $\%$, with increased values for higher temperature and time conditions. The stirring did not show significant influence in the range analyzed (290-570 rpm), which indicates that its presence is important for the homogenization and scale-up of the process, but an accurate value is not necessary.

\section{Elemental analysis}

The obtained values (mass\%) of the degree of functionalization determined by elemental analysis, 
Table 3. Effect of temperature, time and stirring of the factorial design in the degree of functionalization and length of the oxidized MWCNTs

\begin{tabular}{|c|c|c|c|c|c|c|c|c|}
\hline \multirow{2}{*}{ Treatment } & \multicolumn{3}{|c|}{ Parameter } & \multicolumn{2}{|c|}{$\begin{array}{l}\text { Degree of functionalization / } \\
\text { mass } \%\end{array}$} & \multicolumn{3}{|c|}{ Length / $\mu \mathrm{m}$} \\
\hline & $\mathrm{T} /{ }^{\circ} \mathrm{C}$ & $\mathrm{t} / \mathrm{h}$ & $\mathrm{S} / \mathrm{rpm}$ & TGA & $\begin{array}{l}\text { Elemental } \\
\text { analysis }\end{array}$ & $\begin{array}{l}\text { Arithmetic } \\
\text { mean }\end{array}$ & $\begin{array}{l}\text { Weighted } \\
\text { mean }\end{array}$ & $\begin{array}{c}\text { Number of measured } \\
\text { MWCNTs }\end{array}$ \\
\hline- & - & - & - & - & - & $5.3^{\mathrm{a}}$ & $10.1^{\mathrm{a}}$ & 115 \\
\hline 1 & 45 & 2 & 290 & 5.7 & 6.1 & 2.6 & 4.9 & 45 \\
\hline 2 & 45 & 2 & 570 & 6.0 & 6.4 & 3.4 & 5.0 & 68 \\
\hline 3 & 45 & 4 & 290 & 7.5 & 7.8 & 2.3 & 4.3 & 49 \\
\hline 4 & 45 & 4 & 570 & 7.2 & 7.7 & 2.1 & 3.6 & 49 \\
\hline 5 & 55 & 2 & 290 & 8.4 & 9.4 & 2.9 & 4.5 & 47 \\
\hline 6 & 55 & 2 & 570 & 7.7 & 8.9 & 1.7 & 2.8 & 67 \\
\hline 7 & 55 & 4 & 290 & 8.7 & 11.2 & 0.8 & 1.8 & 67 \\
\hline 8 & 55 & 4 & 570 & 9.2 & 9.6 & 1.1 & 2.1 & 62 \\
\hline 9 & 50 & 3 & 430 & 7.9 & 8.8 & 2.9 & 3.7 & 49 \\
\hline 10 & 50 & 3 & 430 & 7.8 & 8.0 & 2.4 & 3.5 & 47 \\
\hline 11 & 50 & 3 & 430 & 7.4 & 8.6 & 2.2 & 3.2 & 65 \\
\hline
\end{tabular}

${ }^{a}$ Pristine MWCNTs. T: temperature; t: time; S: stirring; TGA: thermogravimetric analysis.

considering the oxygen and hydrogen contents, are presented in Table 3. It can be observed a good correlation between the results from both evaluations (except for sample 7), with the values determined by elemental analysis higher in ca. 10\% compared to the TGA data, which is an acceptable difference according to the error associated with both analyses. Therefore, the elemental analysis confirms the influence observed from TGA for the studied variables.

\section{Scanning electron microscopy}

SEM was used to investigate the fragmentation occurred during the different acid treatments performed for the factorial design, as it is well known that the oxidation shortens the tubes. ${ }^{7,11,12}$ The length of MWCNTs was evaluated by the observation of isolated nanotubes in SEM micrographs (see examples in Figure 2). Hundreds of SEM images were used in this study. The average length by both arithmetic and weighted means were determined by measuring 115 pristine MWCNTs and 55 MWCNTs in average after each acid treatment (from 45 to $70 \mathrm{MWCNTs}$ ). The weighted mean is relevant due to the greater weight contribution of longer nanotubes.

The percentage reduction of MWCNTs length can be inferred from Table 3 that shows the average length values for the different treatments and for the pristine sample. It can be noticed that different stirring rates did not significantly influence the length of MWCNTs, the same behavior is
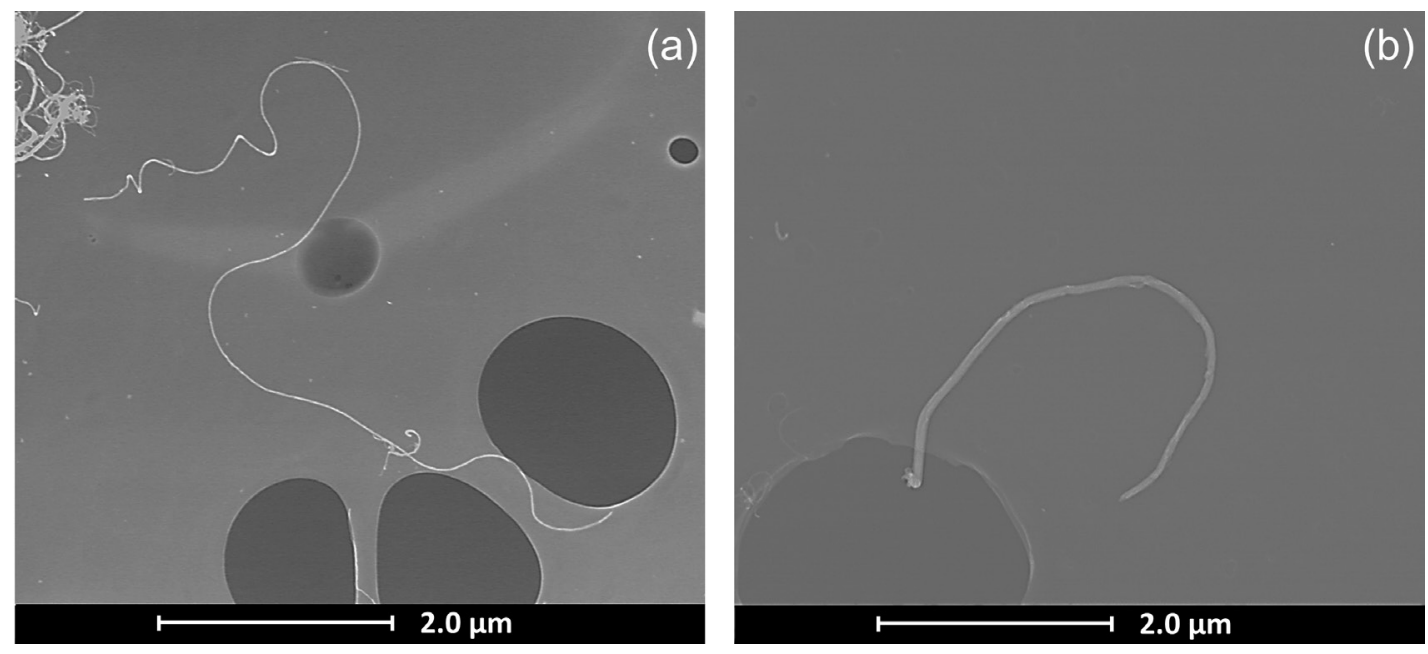

Figure 2. SEM images for (a) pristine MWCNTs and (b) MWCNTs after acid treatment at the center point $\left(50{ }^{\circ} \mathrm{C}, 3 \mathrm{~h}, 430 \mathrm{rpm}\right)$. 
observed for the degree of functionalization. Treatments 1 and 2, carried out with lower time and temperature $\left(45^{\circ} \mathrm{C}\right.$, $2 \mathrm{~h}$ ), resulted in MWCNTs with a greater preservation of length, about $3 \mu \mathrm{m}$ by arithmetic mean and $5 \mu \mathrm{m}$ by weighted mean. The more severe treatments ( 7 and 8 ), with higher time and temperature $\left(55^{\circ} \mathrm{C}, 4 \mathrm{~h}\right)$, cut the MWCNTs down to short tubes, about $1 \mu \mathrm{m}$ by arithmetic mean and $2 \mu \mathrm{m}$ by weighted mean. The other treatments resulted in intermediate and very similar length averages.

Besides the average length values, it is important to analyze the length distributions of the MWCNTs. The pristine MWCNTs exhibit a length distribution with nanotubes mainly up to $10 \mu \mathrm{m}$, but with presence of MWCNTs until $30 \mu \mathrm{m}$. After the different acid treatments, lengths greater than $10 \mu \mathrm{m}$ were no longer observed. Figure 3 shows the length distribution of pristine and oxidized MWCNTs until $15 \mu \mathrm{m}$ to facilitate visualization.
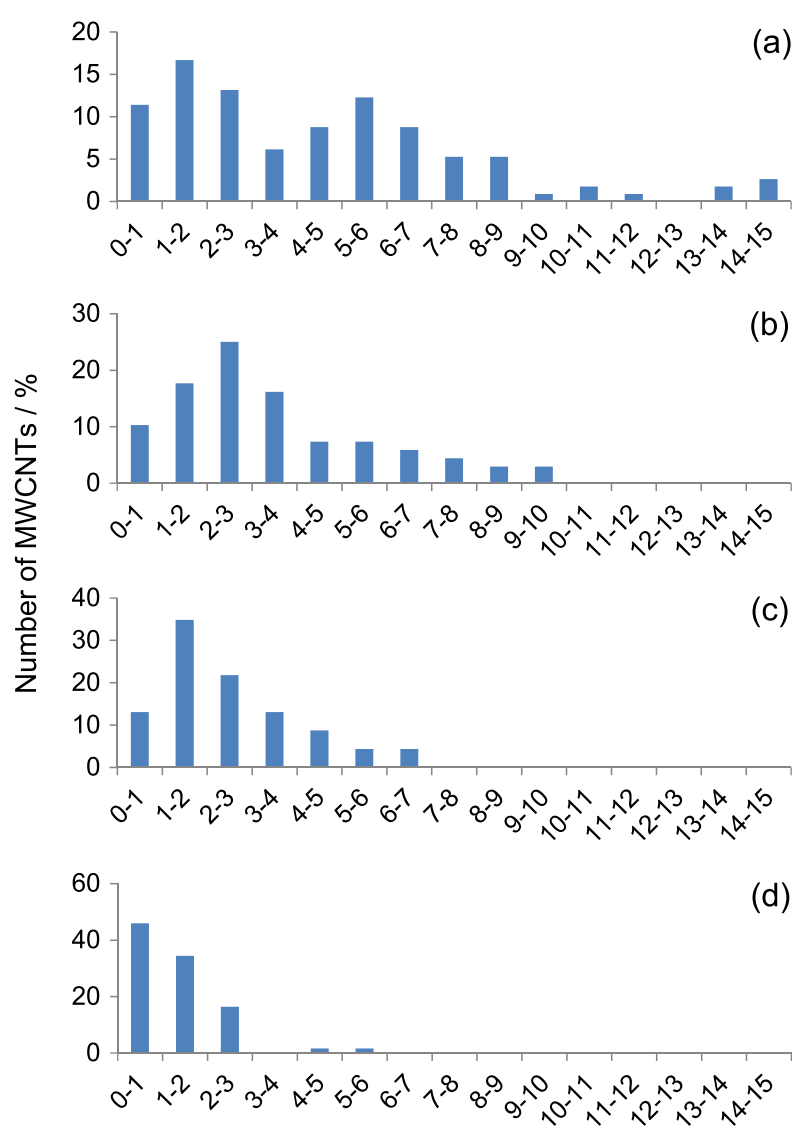

Length of MWCNTs / $\mu \mathrm{m}$

Figure 3. Length distribution of (a) pristine MWCNTs and after (b) treatment 2: $45^{\circ} \mathrm{C}, 2 \mathrm{~h}$; (c) treatment $10: 50{ }^{\circ} \mathrm{C}, 3 \mathrm{~h}$; (d) treatment 8: $55^{\circ} \mathrm{C}, 4 \mathrm{~h}$.

It can be noticed a good preservation of the MWCNTs exposed to treatments at $45^{\circ} \mathrm{C}$ and $2 \mathrm{~h}$, with the presence of MWCNTs until $10 \mu \mathrm{m}$. The MWCNTs after treatments at $50{ }^{\circ} \mathrm{C}$ and $3 \mathrm{~h}$ presented a length distribution up to $7 \mu \mathrm{m}$. Almost all MWCNTs exposed to the most aggressive conditions $\left(55^{\circ} \mathrm{C}\right.$ and $\left.4 \mathrm{~h}\right)$ exhibit length less than $3 \mu \mathrm{m}$.

\section{Statistical evaluation}

The analysis of variance (ANOVA), related to the influence of the studied variables on degree of functionalization (determined by TGA) and length reduction (determined by weighted mean) based on the factorial design results, was conducted and is presented in Figure 4 in the form of a Pareto chart.
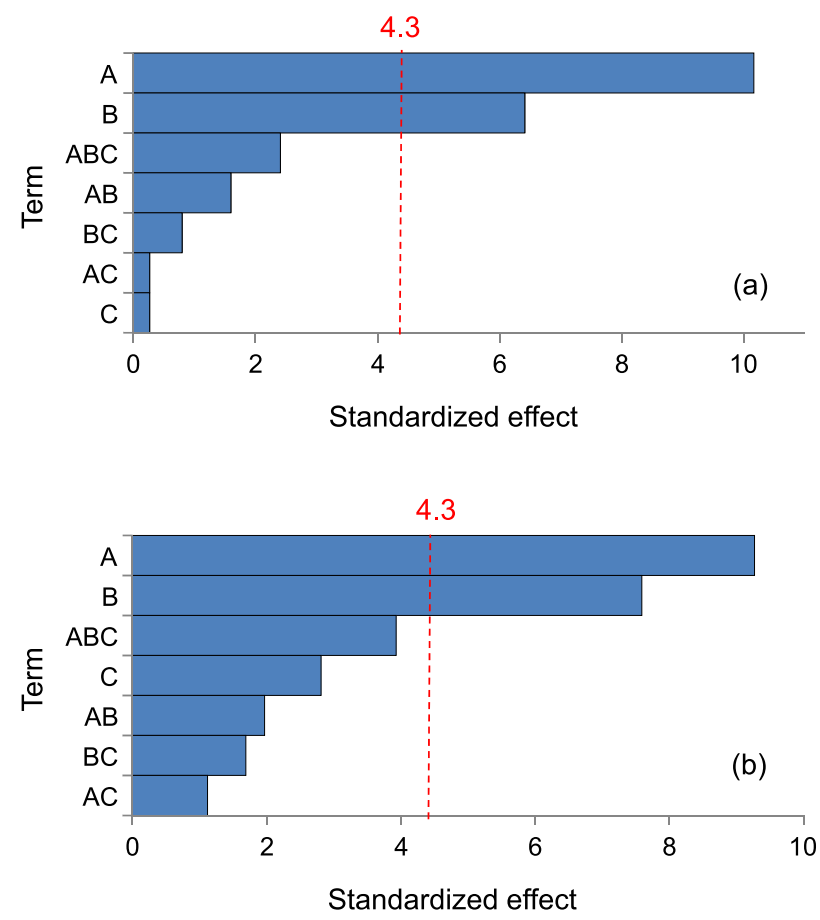

Figure 4. Pareto chart of standardized effect with (a) degree of functionalization and (b) reduction in length as the response variables with significance level $(\alpha)$ of 0.05 . A: temperature; B: time; C: stirring.

The extent of the bar is proportional to the significance of the variables. When the columns exceed the vertical line in the graph, it is inferred that the variables are significant at a confidence level of $95 \%$, which occurs for both temperature (A) and time (B). It was not found influence of the stirring rate $(\mathrm{C})$ and possible interactions of the variables $(\mathrm{AB}, \mathrm{AC}, \mathrm{BC}$ and $\mathrm{ABC})$. Similar results were obtained for the degree of functionalization calculated by elemental analysis and length reduction based on arithmetic mean (data not shown).

The $p$-values indicate the significance of the effects. If the $p$-values are lower than 0.05 , the effects are considered significant with $95 \%$ of probability. It was found a $p$-value lower than 0.003 for the influence of both temperature and 
time in all first-degree polynomial models obtained after eliminating the non-significant terms, which indicates the high significance of these variables. Equations 1 and 2 describe the models for the degree of functionalization calculated by TGA and the length reduction based on weighted mean. The value of $\mathrm{R}^{2}$ was 0.93 for the degree of functionalization, thus with $93 \%$ of the observed variation explained by the variables of the model (temperature, $\mathrm{T}$, and time, $\mathrm{t}$ ). The determined $\mathrm{R}^{2}$ was 0.81 for the length reduction, indicating an inferior fit than the obtained for the degree of functionalization, which was expected due to the largest error involved in measuring the length of MWCNTs.

Degree of functionalization / mass $\%=(7.6 \pm 0.1)+$ $(1.0 \pm 0.1) \mathrm{T}+(0.6 \pm 0.1) \mathrm{t}$

Reduction in length $/ \%=(64 \pm 2)+(8 \pm 2) \mathrm{T}+$ $(7 \pm 2) \mathrm{t}$

The numerical coefficients for $\mathrm{T}$ and $\mathrm{t}$ on equations 1 and 2 can assume values from -1 to +1 (levels of the factorial design, see Table 1). Equation 1 indicates that an increase of $5{ }^{\circ} \mathrm{C}$ or $1 \mathrm{~h}$ provides a degree of functionalization 1.0 and $0.6 \%$ larger, respectively, which highlights that a slight increase of temperature has a high effect in the process. By equation 2, it cannot be noticed a significant difference between the effects of $5^{\circ} \mathrm{C}$ and $1 \mathrm{~h}$ in the length reduction at the ranges studied. Thus, a variation of only $5{ }^{\circ} \mathrm{C}$ promotes a higher increase in the degree of functionalization compared to a variation of $1 \mathrm{~h}$, but with the same reduction in length, indicating that temperature is a better parameter of choice to produce more functionalized MWCNTs with less structural damage.

Similar results were obtained for specific treatment conditions employed for MWCNTs from different batches and suppliers. The numerical responses and the coefficient values for the statistical models oscillate with the characteristics of the pristine MWCNTs (as the defects density, length and diameter). However, the trend of the important role of temperature for a faster functionalization with less structural damage compared to time was maintained.

\section{Raman spectroscopy}

Figure 5 shows the Raman spectra for pristine MWCNTs, oxidized MWCNTs after the mildest treatment $\left(45^{\circ} \mathrm{C}, 2 \mathrm{~h}\right)$ and oxidized MWCNTs after the more severe treatment $\left(55^{\circ} \mathrm{C}, 4 \mathrm{~h}\right)$ of the factorial design.

The characteristic D-band at $1330 \mathrm{~cm}^{-1}$ and G-band at $1580 \mathrm{~cm}^{-1}$ can be identified, which are related to the

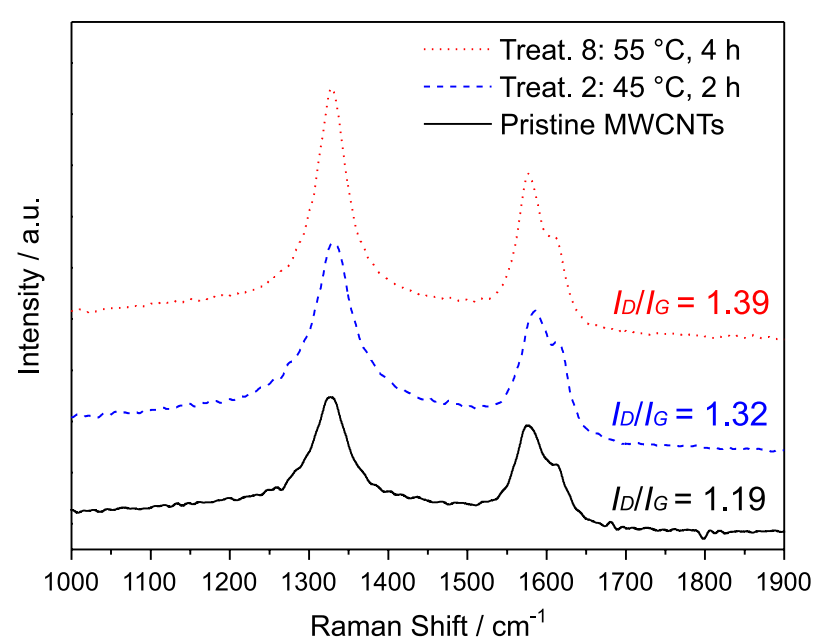

Figure 5. Raman spectra of pristine and oxidized MWCNTs produced by the factorial design.

presence of defects in the graphitic structure and the stretching vibration of $\mathrm{sp}^{2}$ carbon atoms, respectively..$^{14,20,27}$ Therefore, the ratio between the D-band and G-band, noted as $I_{\mathrm{D}} / I_{\mathrm{G}}$, is associated to the degree of defects on the MWCNTs. ${ }^{18,20}$ The D' band can also be observed in Figure 5 as a small shoulder positioned at higher frequencies on the G-band (ca. $1615 \mathrm{~cm}^{-1}$ ), which is associated with disorder of the MWCNTs. ${ }^{27}$ The $I_{\mathrm{D}} / I_{\mathrm{G}}$ ratio was calculated between the intensity of D-band and G-band, without considering the D' band. ${ }^{12,18}$ This ratio increased from 1.19 (pristine MWCNTs) to 1.32 and 1.39 after the treatments $2\left(45^{\circ} \mathrm{C}\right.$, $2 \mathrm{~h})$ and $8\left(55^{\circ} \mathrm{C}, 4 \mathrm{~h}\right)$, respectively. This increase can be attributed to an enhanced proportion of $\mathrm{sp}^{3}$ carbon after the oxidation, as the insertion of functional groups creates defect sites in the MWCNTs..$^{11,18,32}$ The highest $I_{\mathrm{D}} / I_{\mathrm{G}}$ ratio of MWCNTs after treatment at $55{ }^{\circ} \mathrm{C}$ and $4 \mathrm{~h}$ indicates a more functionalized product, as verified by TGA and elemental analysis.

\section{Transmission electron microscopy}

TEM was used to examine the surface morphology change of MWCNTs produced by the acid treatments applied with the conditions of the factorial design. Figure 6 shows representative images for pristine MWCNTs and MWCNTs after the center point treatment $\left(50{ }^{\circ} \mathrm{C}, 3 \mathrm{~h}\right)$.

TEM micrograph of pristine MWCNTs (Figure 6a) shows well aligned graphitic walls. It can be noticed relatively little disturbance in the surface distribution of walls after the acid treatment (Figure 6b). Nevertheless, the presence of oxygenated carbonaceous fragments (pointed by arrow) around the surface of treated nanotubes can be observed in Figure 6b, which has also been noticed in other oxidation studies of CNTs. ${ }^{10,17}$ A larger number of TEM 

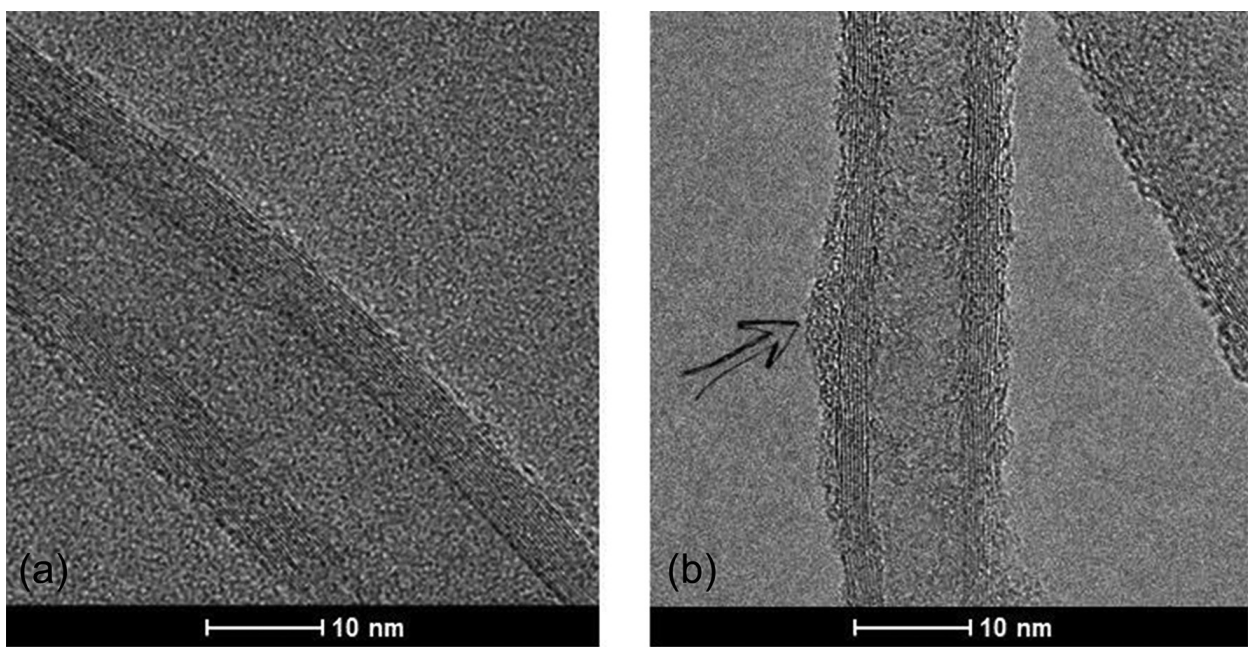

Figure 6. TEM images for (a) pristine MWCNTs and (b) MWCNTs after acid treatment at the center point $\left(50{ }^{\circ} \mathrm{C}, 3 \mathrm{~h}\right)$.

micrographs for these MWCNTs are given in Figures S1-S2 (Supplementary Information).

\section{Dispersion analysis}

The analysis of dispersion stability of CNTs in aqueous and organic media is a common method to qualitatively assess the presence of functional groups..$^{10,11,17,18,25}$ Figure 7 shows photographs of the MWCNT/water dispersions for the main experiments of the factorial design.

It can be noticed that practically all pristine MWCNTs (Figure 7a) sedimented, while the MWCNTs after acid treatment for $2 \mathrm{~h}$ at $45{ }^{\circ} \mathrm{C}$ partially sedimented (Figure $7 \mathrm{~b}$ ) and the other modified MWCNTs remained well-dispersed after 30 days (Figures 7c-7f). As the presence of oxygencontaining groups improves the stability of MWCNTs in polar media, ${ }^{32,37}$ these results are in agreement with the observation by TGA and elemental analysis, which revealed a superior percentage of functional groups for treatments with higher temperature and time. Therefore, the degree of functionalization obtained by the treatment with $2 \mathrm{~h}$ and $45^{\circ} \mathrm{C}$ promoted only a partial dispersion, but all treatments with higher temperature and/or time were sufficient to guarantee a long-term dispersion. The electrostatic repulsion between the functional groups inserted in these treatments and the interactions with water prevailed over the van der Waals forces, forming the Stern layer around the MWCNTs surrounded by a diffuse layer of water molecules (Figure 8). The presence of carboxyl groups is especially important due to its higher acidity compared to phenolic hydroxyls and lactones/lactols. ${ }^{10}$

\section{Yield evaluation}

The yield obtained for treatments with higher temperature and time $\left(55^{\circ} \mathrm{C}, 4 \mathrm{~h}\right)$ was 95 mass $\%$ and the yields for the remaining experiments were between 100 and 104 mass \%. The mass loss for the treatments with the highest factor values arises from increased fragmentation of MWCNTs and passage of a small fraction through the filter medium during washing, which is in agreement with the reduction of length observed from SEM. The

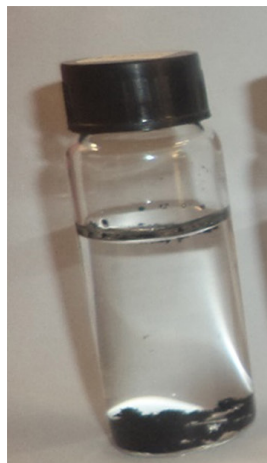

(a)

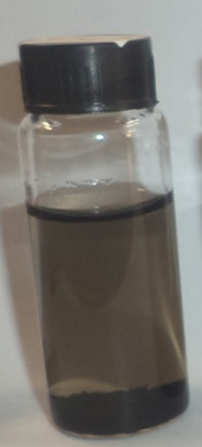

(b)

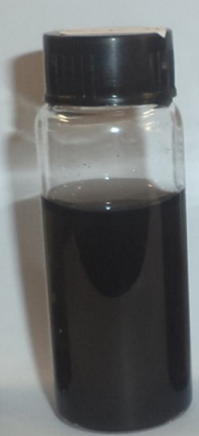

(c)

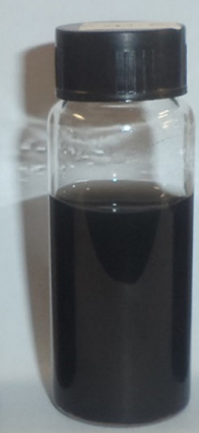

(d)

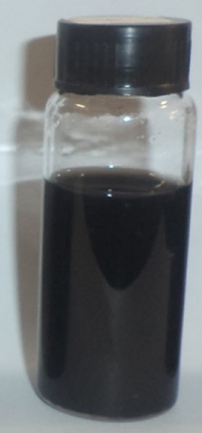

(e)

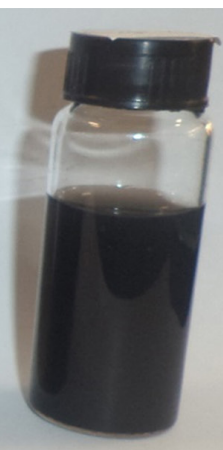

(f)

Figure 7. Dispersions in water after 30 days for (a) pristine MWCNTs and after (b) treatment $2: 45^{\circ} \mathrm{C}, 2 \mathrm{~h}$; (c) treatment $4: 45^{\circ} \mathrm{C}, 4 \mathrm{~h}$; (d) treatment 6 : $55^{\circ} \mathrm{C}, 2 \mathrm{~h}$; (e) treatment $8: 55^{\circ} \mathrm{C}, 4 \mathrm{~h}$; (f) treatment $10: 50{ }^{\circ} \mathrm{C}, 3 \mathrm{~h}$. 


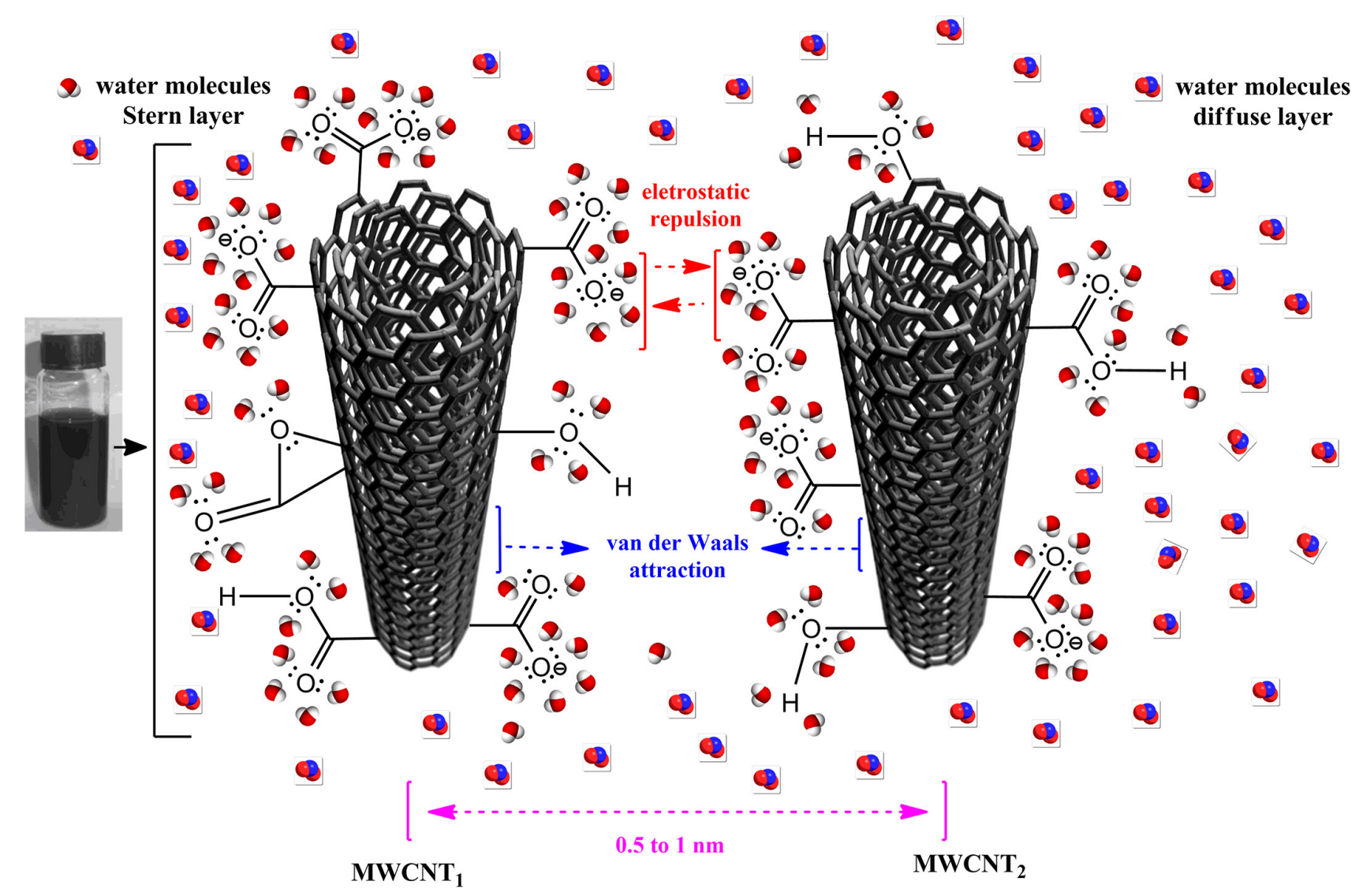

Figure 8. Illustrative scheme of colloidal dispersions of functionalized MWCNTs in water.

yields greater than 100 mass $\%$ are due to the insertion of functional groups on the surface of MWCNTs. As literature generally reports yields between 70 and $90 \%,,^{11,19,32}$ the process presented in this work has a high efficiency in the production of functionalized MWCNTs.

\section{Conclusions}

According to the obtained results, the acid treatment method using ultrasound, moderate heating and mechanical stirring can be successfully applied for an effective functionalization of MWCNTs with high yield. The process is scalable due to the presence of stirring and the degree of functionalization and reduction in length are proportional to both temperature and time. A slight variation of $5{ }^{\circ} \mathrm{C}$ increases the degree of functionalization in 1 mass $\%$, an enhanced effect compared to $1 \mathrm{~h}$ longer, with the same impact on the fragmentation of nanotubes. This kind of result was not yet clearly established in the field. Therefore, temperature is an important variable to promote a fast functionalization of MWCNTs with enhanced preservation of its structure.

By the statistical modeling developed, the functionalization process can be adjusted to achieve a set of properties for each specific end-use application, like polymeric composites or biological systems. The control of degree of functionalization and length distribution of MWCNTs is extremely useful for the fabrication of several polymeric composites, ${ }^{5,38}$ which request an effective functionalization with less structural damage of MWCNTs. Treatments with enhanced temperature and time, which produce highly functionalized and short MWCNTs with narrow length distribution, can be employed for different bio-related applications. ${ }^{19,37}$

\section{Supplementary Information}

Supplementary information (TEM micrographs of pristine and modified MWCNTs, Figures S1-S2) is available free of charge at http://jbcs.org.br as PDF file.

\section{Acknowledgments}

The authors acknowledge the Petrobras Company for the funding and the elemental analysis, the CNPq for the financial support and the Microscopic Center (UFMG) for the electron microscopy images. 


\section{References}

1. Meyyappan, M.; Small 2016, 12, 2118.

2. Mehra, N. K.; Jain, K.; Jain, N. K.; Drug Discovery Today 2015, 20,750 .

3. Zhang, Q.; Huang, J.; Qian, W.; Zhang, Y.; Wei, F.; Small 2013, 9, 1237.

4. De Volder, M. F. L.; Tawfick, S. H.; Baughman, R. H.; Hart, A. J.; Science 2013, 339, 535.

5. Spitalsky, Z.; Tasis, D.; Papagelis, K.; Galiotis, C.; Prog. Polym. Sci. 2010, 35, 357.

6. Karousis, N.; Tagmatarchis, N.; Tasis, D.; Chem. Rev. 2010, 110, 5366.

7. Kim, S. W.; Kim, T.; Kim, Y. S.; Choi, H. S.; Lim, H. J.; Yang, S. J.; Park, C. R.; Carbon 2012, 50, 3.

8. Bilalis, P.; Katsigiannopoulos, D.; Avgeropoulos, A.; Sakellariou, G.; RSC Adv. 2014, 4, 2911.

9. Hanelt, S.; Orts-Gil, G.; Friedrich, J.; Meyer-Plath, A.; Carbon 2011, 49, 2978.

10. Chen, J.; Chen, Q.; Ma, Q.; J. Colloid Interface Sci. 2012, 370, 32.

11. Avilés, F.; Cauich-Rodriguez, J.; Moo-Tah, L.; May-Pat, A.; Vargas-Coronado, R.; Carbon 2009, 47, 2970.

12. Worsley, K. A.; Kalinina, I.; Bekyarova, E.; Haddon, R. C.; J. Am. Chem. Soc. 2009, 131, 18153.

13. Wang, Z.; Shirley, M. D.; Meikle, S. T.; Whitby, R. L.; Mikhalovsky, S. V.; Carbon 2009, 47, 73.

14. Scheibe, B.; Borowiak-Palen, E.; Kalenczuk, R. J.; Mater. Charact. 2010, 61, 185.

15. Silva, W. M.; Ribeiro, H.; Seara, L. M.; Calado, H. D.; Ferlauto, A. S.; Paniago, R. M.; Leite, C. F.; Silva, G. G.; J. Braz. Chem. Soc. 2012, 23, 1078.

16. Bertoncini, M.; Hoepfner, J. C.; Pezzin, S. H.; Curr. Org. Chem. 2013, 17, 1838.

17. Vukovic', G.; Marinkovic, A.; Obradovic, M.; Radmilovic, V.; Miodrag, C.; Aleksic, R.; Uskokovic, P. S.; Appl. Surf. Sci. 2009, 255, 8067.

18. Osorio, A. G.; Silveira, I. C. L.; Bueno, V. L.; Bergmann, C. P.; Appl. Surf. Sci. 2008, 255, 2485.

19. Samorì, C.; Sainz, R.; Ménard-Moyon, C.; Toma, F. M.; Venturelli, E.; Singh, P.; Ballestri, M.; Prato, M.; Bianco, A.; Carbon 2010, 48, 2447.
20. Wepasnick, K. A.; Smith, B. A.; Schrote, K. E.; Wilson, H. K.; Diegelmann, S. R.; Fairbrother, D. H.; Carbon 2011, 49, 24.

21. Farahani, B. V.; Behbahani, G. R.; Javadi, N.; J. Braz. Chem. Soc. 2016, 27, 694.

22. Mazov, I.; Kuznetsov, V. L.; Simonova, I. A.; Stadnichenko, A. I.; Ishchenko, A. V.; Romanenko, A. I.; Tkachev, E. N.; Anikeeva, O. B.; Appl. Surf. Sci. 2012, 258, 6272.

23. Smith, B.; Wepasnick, K.; Schrote, K. E.; Cho, H.; Ball, W. P.; Fairbrother, D. H.; Langmuir 2009, 25, 9767.

24. Chiang, Y.; Lin, W.-H.; Chang, Y.; Appl. Surf. Sci. 2011, 257, 2401.

25. Zhao, Z.; Yang, Z.; Hu, Y.; Li, J.; Fan, X.; Appl. Surf. Sci. 2013, $276,476$.

26. Cho, J.; Boccaccini, A. R.; Shaffer, M. S.; Carbon 2012, 50, 3967.

27. Datsyuk, V.; Kalyva, M.; Papagelis, K.; Parthenios, J.; Tasis, D.; Siokou, A.; Kallitsis, I.; Galiotis, C.; Carbon 2008, 46, 833.

28. Zhang, X.; Deng, C.; Xu, R.; Wang, D.; J. Mater. Sci. 2007, 42, 8377.

29. Li, Y.; Li, H.; Petz, A.; Kunsági-Maté, S.; Carbon 2015, 19, 515.

30. Blanchard, N.; Hatton, R.; Silva, S.; Chem. Phys. Lett. 2007, 434, 92.

31. Yu, H.; Jin, Y.; Peng, F.; Wang, H.; Yang, J.; J. Phys. Chem. C 2008, 112, 6758 .

32. Kitamura, H.; Sekido, M.; Takeuchi, H.; Ohno, M.; Carbon 2011, 49, 3851.

33. Zhou, W.; Sasaki, S.; Kawasaki, A.; Carbon 2014, 78, 121.

34. Wu, Z.; Hamilton, R. F.; Wang, Z.; Holian, A.; Mitra, S.; Carbon 2014, 68, 678 .

35. Hojati-Talemi, P.; Cervini, R.; Simon, G. P.; J. Nanopart. Res. 2010, 12, 393.

36. Ciambelli, P.; Sannino, D.; Sarno, M.; Leone, C.; Thin Solid Films 2011, 519, 2121.

37. Heister, E.; Lamprecht, C.; Neves, V.; Tilmaciu, C.; Datas, L.; Flahaut, E.; Soula, B.; Hinterdorfer, P.; Coley, H. M.; Silva, S. R. P.; ACS Nano 2010, 4, 2615.

38. Byrne, M. T.; Gun'ko, Y. K.; Adv. Mater. 2010, 22, 1672.

Submitted: August 6, 2016

Published online: October 11, 2016 